\title{
ITF

\section{Plantar pressures differences between the flat, slice and topspin serves}

\author{
Christos Mourtzios ${ }^{a}$, Eleftherios Kellis ${ }^{a}, \&$ Konstantinos Salonikidis ${ }^{a}$ \\ ${ }^{a}$ Aristotle University of Thessaloniki, Greece.
}

\section{ABSTRACT}

Analysis of plantar pressure during sport movement performance can provide significant information to athletes and coaches regarding sport performance and plantar loads. In tennis, the serve is one of the most difficult and most important strokes. The purpose of this study was to examine the plantar pressure differences between the flat, slice and topspin serves with the "foot back" serving technique on greenest tennis surfaces of junior athletes aged 10 to 16 . The results showed that the loads were higher on the rear (right) back foot of all the three serves. The Fmax was higher in foot toes for all types of serve and the peak pressure was higher in slice serve in the metatarsal forefoot region of the back right foot. The results showed that the technique applied, mainly to the footwork, varies between types of serves. So, each type of the three serves has different loads.

\author{
Key words: plantar pressures, \\ serve, flat, slice, topspin. \\ Received: 06 March 2019 \\ Accepted: 20 June 2019 \\ Corresponding author: Christos \\ Mourtzios, Laboratorio de \\ Neuromecánica, Departamento \\ de Educación Física y Ciencias \\ del Deporte de Serres, \\ Universidad Aristóteles de \\ Salónica, Grecia. Email: \\ christosmourtzios@hotmail.gr
}

\section{INTRODUCTION}

In the game of tennis, the serve is recognized as the most important offensive weapon. According to Elliot \& Colett (1993) the primary source of power is generated from the ground in the form of ground reaction force, which is emitted by the ground on the body as the server pushes against it.

According to Hutchinson et al., (1995), injuries that required physical or medical assistance were recorded for participants at the United States Tennis Association National Boys' Tennis Championships. The analysis of injuries showed a higher rate of lower than upper extremity injuries. When evaluated by injury type, strains and sprains were most common ( $71 \%$ of all injuries) with fractures and dislocations being rare (1.3\% of all injuries). The lower extremity provided the majority of sprain type injuries with $87.5 \%$ of ligament sprains coming from the knee and ankle.

In the back foot, the relative loads are distributed across the foot more equally and with a lower variability (smaller coefficient of variation) than in the front foot. This suggests that the back foot is a large base for force production and the starting point for the kinetic chain that goes from the ground to the leg, trunk, upper body segments, and finally the racquet (Bahamonde, 2000).

Analysis of plantar pressures, allowing documentation of a very powerful prognostic model in the initial functional ability of an athlete. Using the measurements and monitoring possible changes, positive or negative in the effort to improve technique, these data can greatly enhance improve athletic condition. The identification of the differences between the three types of serve may be the regulation of the intensity of training, the control of these variables in order to prevent the development of injuries and improve technique. Girard et al. (2010) concluded that, the type of serve and the stance style adopted have a significant effect on foot loading. Such findings might help improve mechanical efficiency of the serve.

To our knowledge, no data on plantar pressure distribution has been published for junior athletes for the tennis serve. The aim of this study was to measure and examine the plantar pressures, of junior tennis athletes during the three different serves, flat, slice and topspin, on green set surface with the "foot back" serving technique.

\section{METHODS}

Fifteen (8 males, 7 females) right handed tennis players, aged 10-16 years (three under-10 years, four under- 12 years, four under-14 years, four under-16 years, participated in this study, that are playing in tournaments of the Hellenic Tennis Federation. All experiments were conducted on an outdoor greenset tennis court. 


\section{Instrumentation}

Plantar pressures and vertical ground reaction forces were recorded using the footscan insole 2.39 system (RSscan International, Paal, Belgium). During data collection, the insoles were placed between the shoe and the surface of the sole on both feet. The data logger for storing the data was secured around the waist of the athlete's body. The data was transferred to a laptop at a sampling rate of $500 \mathrm{~Hz}$.

\section{Experimental set-up}

Players performed a standardized warm-up which was followed by a 10-min of practice with each of the three serves. All serve trials were completed from the deuce court. Three successful trials were collected for each type of serve.

During data collection, the insole was placed between the shoe and the surface sole of both feet. The data logger for storing the data was located around the waist of the athlete's body.

\section{Data analysis}

A regional analysis of the foot was performed on the recorded plantar pressure data by dividing the foot into four separate areas: Toes, Forefoot, Midfoot and Heel. Subsequently, the following parameters were determined for the whole foot and the four selected regions: maximum and mean force, peak and mean pressure.

\section{RESULTSWITH DISCUSSION}

To our knowledge, no data on plantar pressure distribution during tennis movements have been published for tennis junior athletes. Furthermore, differences in plantar pressures between the flat, slice and topspin serves have not been previously investigated.

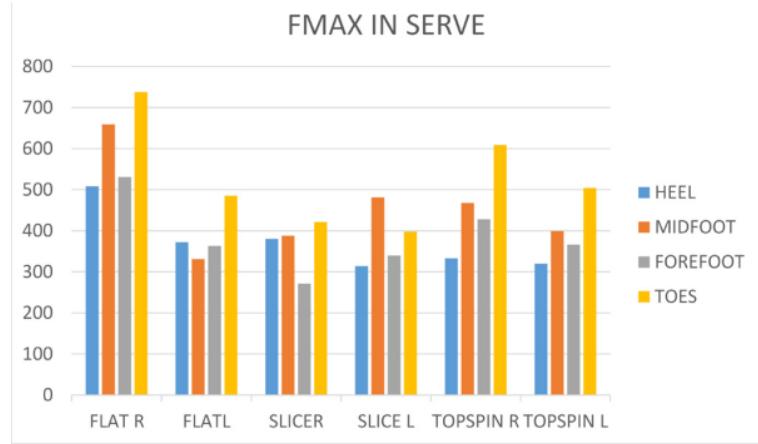

Table 1: Fmax (N) in flat, slice and topspin serves for different areas of the foot

The results showed that the loads were higher on the rear (right) back foot of all the three serves. The rear leg provides the bulk of the upward and forward push, while the front foot provides a stable position to allow angular momentum development. Consequently, it appears that when right handed tennis junior athletes perform a tennis serve the right foot displays highest plantar pressures, which result in the initiation of sequence of serve movements as the foot contacts the ground and subsequently contribute to the leg drive. So, coaches have to explain to their athletes for this phase of loading the importance of the rear foot, so they can achieve a better result of the upward and forward push and a better transfer of forces. The Fmax was higher in foot toes for all types of serve, with the highest value observed in the flat serve, then in topspin and last in slice serve. This can be attributed to the usage of each serve, as the flat serve is frequently used as first serve, and, hence it is executed with more power and speed. Also, Fmax in the region of the foot was higher in midfoot, then in forefoot and last in heels.

The peak pressure was higher in slice serve in the metatarsal forefoot region of the back foot, because of a higher knee bend $\left(\geq 20^{\circ}\right)$ during the preparation phase of second serves as slice and topspin that are used (Lo, Wang, Wu, \& Su, 2004). Also, the peak pressure was higher in the metatarsal forefoot region in all 3 types of serves in both feet. Finally, the peak pressures were higher in the back right foot in all 3 types of serves.

The results of the present study indicate that both the front and back foot are loaded differently for junior athletes, based on the type of serve. Coaches must understand the mechanical basis of the three types of tennis serves. So, when the junior players are performing tennis serves to be able to generate more racquet speed, they must work hard on the loading phase specifically at the time when the maximum loads are on the toes as this results in transfer of as much force as possible to the upper part of the body, thus optimising the kinetic chain.

\section{PROPOSALS}

Research in plantar pressure distribution when performing tennis movements may continue in-depth, because it can help athletes of all levels (i.e. beginners or advanced players), to improve their skills, in cooperation with the biomechanics in order to have higher performance, better results and fewer injuries in the sport of tennis.

Finally, the study of lower limbs and plantar pressures is important for young tennis athletes, because this research will extend the knowledge about the technique and the type of service so that specific strategies for training, prevention and rehabilitation of injuries, are very important for the development of young athletes.

\section{CONCLUSIONS}

This study is the first that analyzes plantar pressures through the three different basic serves for junior athletes. The results showed that the technique applied, mainly to the footwork, varies between types of serves. The study of plantar pressure loads can effectively help athletes and coaches to produce better results allowing for a better start of the kinetic chain and allowing for leg drive that produces more powerful serves with better technique and fewer injuries. 


\section{REFERENCES}

Bahamonde, R.E. (2000). Changes in angular momentum during the tennis serve. J Sports Sci 18 (8):579-592, https://doi.org/10.1080/02640410050082297

Chow, J.W., Carleton, L.G., Lim, Y.T., Chae, W.S., Shim. J.H., Kuenster. A.F., \& Kokobun, K. (2003). Comparing the pre- and post- impact ball and racquet kinematics of elite tennis players' first and second serves: a preliminary study. J Sports Sci. 21 (7):529-537, https://doi.org/10.1080/0264041031000101908

Elliott, B., \& Colette, D. (1993) Biomechanics. ITF Coaching and Sport Science Review, 1, 11.

Girard, O., Micallef, J.P., \& Millet, G.P. (2010). Effects of the playing surface on plantar pressures during the first serve in tennis. International Journal of Sports Physiology and Performance, 5(3), 384-393, https://doi.org/10.1123/ijspp.5.3.384

Girard, O., Eicher F., Micallef, J.P., \& Millet, G.P. (2010). Plantar pressures in the tennis serve. Journal of Sports Sciences, June 28(8): 873-880, https://doi.org/10.1080/02640411003792695

Hutchinson, M. R., Laprade, R. F., Burnett, Q. M., Moss, R., \& Terpstra, J. (1995). Injury surveillance at the USTA Boys' tennis championships: A 6-yr study. Med Sci Sports Exerc, 27(6), 826830, https://doi.org/10.1249/00005768-199506000-00006

RECOMMENDED ITF TENNIS ACADEMY CONTENT (CLICK BELOW)

\section{ITF Academy}

Copyright (c) 2019 Christos Mourtzios, Eleftherios Kellis, \& Konstantinos Salonikidis

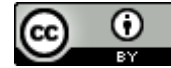

This text is under a Creative Commons BY 4.0 license

You are free to Share - copy and redistribute the material in any medium or format - and Adapt the content - remix, transform, and build upon the material for any purpose, even commercially under the following terms:

Attribution: You must give appropriate credit, provide a link to the license, and indicate if changes were made. You may do so in any reasonable manner, but not in any way that suggests the licensor endorses you or your use.

CCBY 4.0 license terms summary $\quad$ CCBY4.0license terms 